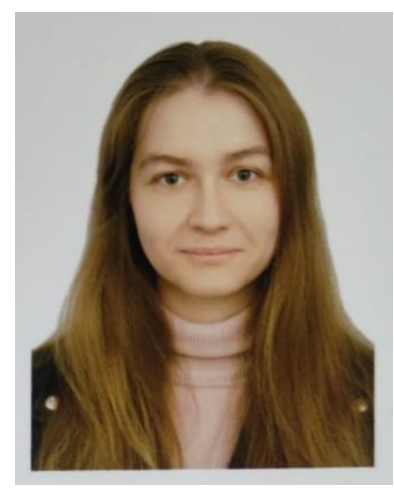

\title{
МЕТОДИКА ОБОБЩЁННОЙ ЧИСЛЕННОЙ ОРГАНОЛЕПТИЧЕСКОЙ ОЦЕНКИ КАЧЕСТВА НАТУРАЛЬНЫХ СИДРОВ, ОБОГАЩЁННЫХ СИРОПАМИ ИЗ ДИКОРАСТУЩИХ ПЛОДОВ И ЯГОД
}

\author{
А. Кошкина, магистрант 1-го курса, \\ e-mail: Anastasija.koskina@gmail.com \\ ФГБОУ ВО «Калининградский государственный \\ технический университет» \\ Д. Л. Альшевский, канд. техн. наук, доц., \\ e-mail: alshevsky@klgtu.ru \\ ФГБОУ ВО «Калининградский государственный \\ технический университет»
}

Для органолептической оценки качества и вкуса сидра с различными рецептурными компонентами были разработаны две оценочные таблицы. Одна из таблиц позволяет оценить общее впечатление о продукте и дать ему качественную оценку, вторая предназначена для выявления основных вкусо-ароматических нот в сидре и установить типичные привкусы вносимых сиропов из дикорастущего сырья, аналогично винному и кофейному колесу ароматов.

Ключевые слова: органолептическая оценка, сидр, колесо ароматов, дескрипторы, органолептическая таблица

\section{ВВЕДЕНИЕ}

При производстве любого из продуктов питания важно учитывать не только его безопасность относительно здоровья потребителя, но и органолептические качества продукта. В настоящее время на пищевом рынке делается акцент на натуральные вкусы и ароматы, при этом как производителям, так и потребителям важно уметь описывать вкус и аромат продукта не только субъективно «нравится»/«не нравится», но и с объективной точки зрения, таким образом, чтобы людям, не знакомым с продуктом, было понятно, на что он похож по консистенции, вкусу, с чем можно сравнить его аромат.

\section{ОБЪЕКТ ИССЛЕДОВАНИЯ}

Объектами исследования были образцы яблочного сидра, в различной степени обогащённые сиропами из дикорастущих плодов и ягод Калининградской области, а именно облепиха крушеновидная (лат. Hippóphaë rhamnóides), шиповник морщинистый (лат. Rósa rugósa) и калина обыкновенная (лат. Vibúrnum ópulus).

\section{ЦЕЛИ И ЗАДАЧИ ИССЛЕДОВАНИЯ}

Цель работы - провести органолептическую оценку яблочного сидра с различными натуральными наполнителями и выявить основные вкусовые и ароматические ноты разных образцов сидра.

Для достижения цели необходимо разработать разные органолептические оценочные шкалы, важно создать их как можно более понятными для дегустационной комиссии и узконаправленными, относящимися именно к такому продукту, как яблочный сидр с добавлением сиропов из дикорастущего сырья. 


\section{МЕТОДЫ ИССЛЕДОВАНИЯ}

Для обобщённой численной органолептической оценки качества была разработана 50-балльная шкала, представленная на рис. 1, включающая четыре основных характеристики сидра и их расшифровку. Баллы были распределены согласно значимости характеристики.

\section{Оценка}

Внешний вид :

Цвет бледный-соломенный-з олотистый-янтарный-абрикосовый-медный Прозрачность мутный-туманный-чистый-кристальный

Яркость блёклый-яркий-насыщенный

Карбонизация не газированный - средне газированный-сильно газированный
Горечь Для заметок

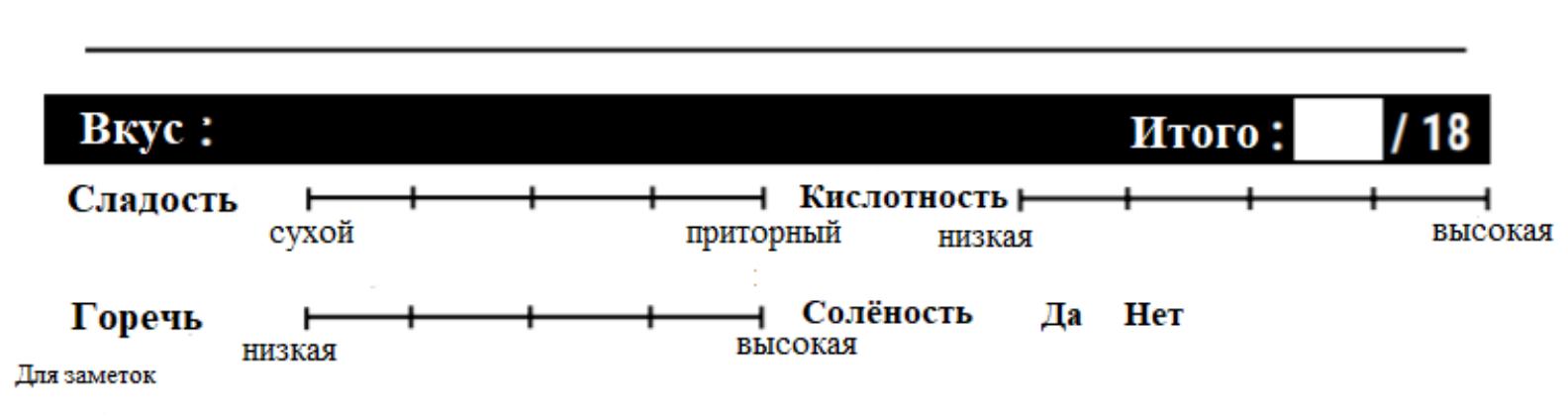

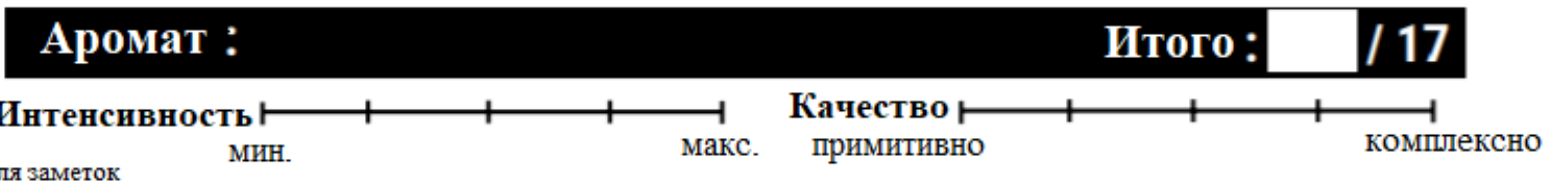

\section{Ито}

Итого: / / 17

\author{
(1)
}

(1)

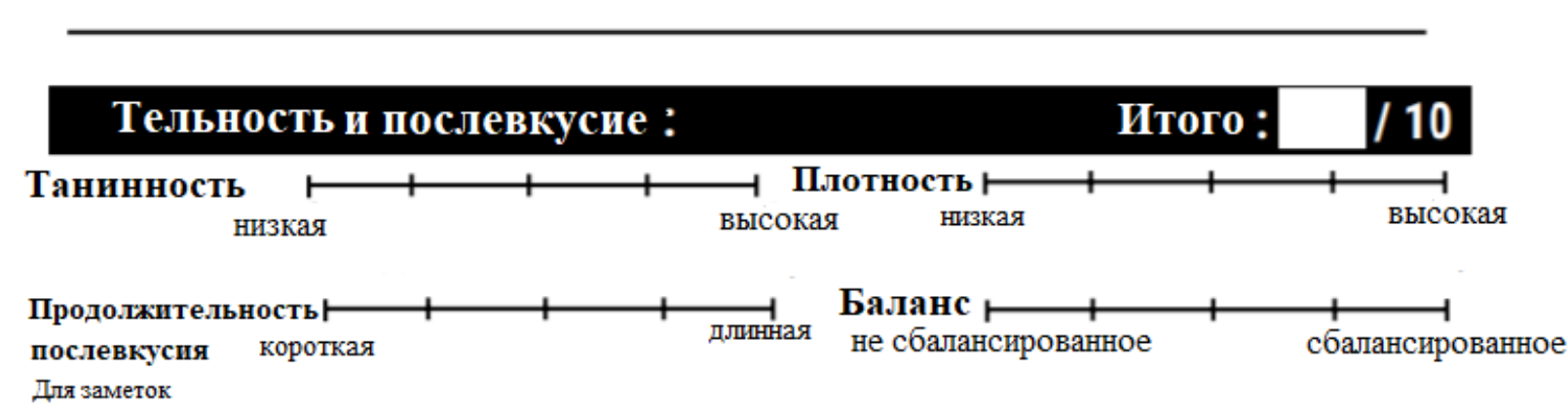

\section{Общая оценка: $1 / 50$}

Рисунок 1 - Шкала органолептической оценки яблочного сидра

Для создания шкалы вкусов сидра необходимо описать все возможные вкусы и послевкусия, которые потенциально можно почувствовать при дегустации яблочного сидра. Таким образом, в табл. 1 представлены дескрипторы вкусов сидра, каждый из которых предлагается оценить от 0 до 5 , где 0 означает отсутствие дескриптора в букете, а 5 наиболее яркое и чистое ощущение того или иного привкуса $[1,2]$. 
Таблица 1 - Вкусовые дескрипторы сидра

\begin{tabular}{|c|c|c|c|c|c|c|c|}
\hline \multicolumn{2}{|l|}{ № 1. Кислая } & \multicolumn{2}{|c|}{ № 3 Специи, травы, орехи } & \multicolumn{2}{|l|}{ № 7 Серные } & \multicolumn{2}{|c|}{ № 11 Ощущение во рту } \\
\hline \multicolumn{2}{|c|}{ Едкий } & \multirow[t]{3}{*}{ Специи } & Смола, хвоя & Серный & & Щелочное & \\
\hline \multicolumn{2}{|c|}{ Острая яблочная кислота } & & Древесина & Диоксид серы & & Металлическое & \\
\hline \multicolumn{2}{|c|}{ Уксусная кислота } & & Горькие специи & \multirow[t]{7}{*}{ Сульфиды } & Испорченное яйцо & Вяжущее & Сушащее \\
\hline \multicolumn{2}{|c|}{$\begin{array}{l}\text { Мягкая молочная кислота } \\
\text { Лимонная кислота }\end{array}$} & \multirow[t]{2}{*}{ Орехи } & Грецкий & & Сточные воды & Зернистое & \\
\hline \multicolumn{2}{|c|}{ Лимонная кислота } & & Миндаль & & $\begin{array}{l}\text { Разлагающееся } \\
\text { мясо }\end{array}$ & Кремовое & \\
\hline \multicolumn{2}{|c|}{ № 2. Ароматы, фрукты, цветы } & \multirow[t]{2}{*}{ Трава } & Свежая трава & & Горелая резина & \multirow[t]{2}{*}{ Газированное } & Без газов \\
\hline \multirow[t]{2}{*}{ Алкоголь } & Винный & & Сено & & Креветочный & & С газами \\
\hline & Сивушный & \multicolumn{2}{|c|}{ № 4 Карамельность, жжёный привкус } & & $\begin{array}{l}\text { Приготовленные } \\
\text { овощи }\end{array}$ & Согревающее & \\
\hline \multirow[t]{2}{*}{ Химический } & Пластик & \multirow[t]{2}{*}{ Карамель } & Меласса & & $\begin{array}{l}\text { Приготовленная } \\
\text { капуста }\end{array}$ & \multicolumn{2}{|c|}{ № 12 Полнотелость } \\
\hline & Ацетон & & Изюм & Дрожжевой & Мясной & \multirow[t]{4}{*}{ Тело } & Водянистое \\
\hline \multirow[t]{3}{*}{ Эфирный } & Грушевый & \multirow[t]{2}{*}{ Жжёный } & Поджаренный & \multicolumn{2}{|c|}{ № 8 Окисленные, залежалые, затхлые } & & Бесхарактерное \\
\hline & Яблочно-анисовый & & Жжёной резины & Лежалый & & & Насыщенное \\
\hline & $\begin{array}{l}\text { Слегка } \\
\text { фруктовый(этилацетат) }\end{array}$ & \multicolumn{2}{|l|}{ № 5 Химические } & Кошачий & & & Густое \\
\hline \multirow[t]{12}{*}{ Фруктовый } & Цитрус & \multirow[t]{4}{*}{ Фенолы } & Дегтярный & Бумажный & & & \\
\hline & Банан & & Карболовый & Кожаный & & & \\
\hline & Чёрная смородина & & Антисептический & Плесень & Землистая & & \\
\hline & Дыня & & Йодоформ & & Затхлая & & \\
\hline & Груша & Пластик & & № 9 Сладкий & & & \\
\hline & & & & & Мёд & & \\
\hline & Лесные ягоды & Масло & Минеральное & & Сахарин & & \\
\hline & Печёное яблоко & & Овощное & & Ваниль & & \\
\hline & Сладко-горькое яблоко & Индол & & & Сироп & & \\
\hline & Облепиха & № 6 Мыльные, жи & ге, диацетил & № 10 Горький & & & \\
\hline & Шиповник & Жирные кислоты & Мыльный & Горький & & & \\
\hline & Калина & & Сырный & & & & \\
\hline Ацетальдегид & & & Прогорклое масло & & & & \\
\hline Цветочные & Роза & Ириска & & & & & \\
\hline & Герань & Тухлый & & & & & \\
\hline & Парфюмерный & & & & & & \\
\hline
\end{tabular}


Производственная дегустация выполнялась в лаборатории кафедры технологии продуктов питания ФГБОУ ВО «КГТУ», дегустационная комиссия состояла из семи человек, рабочие места которых были подготовлены, согласно ГОСТ 32051-2012, приложение А п. 3.1.3 [3]. Также дегустаторы заранее были ознакомлены с технологическими особенностями производства и прошли инструктаж по методам органолептического анализа.

Для удобства представления результатов, образцам были присвоены следующие номера: яблочный сидр с добавлением $25 \%$ облепихового вкусового обогатителя - № 1 , яблочный сидр с добавлением 50 \% облепихового вкусового обогатителя - № 2, яблочный сидр с добавлением 75 \% облепихового вкусового обогатителя - № 3, яблочный сидр с добавлением $25 \%$ вкусового обогатителя на основе ягод калины - № 4, яблочный сидр с добавлением 50 \% вкусового обогатителя на основе ягод калины - № 5, яблочный сидр с добавлением $75 \%$ вкусового обогатителя на основе ягод калины - № 6, яблочный сидр с добавлением $25 \%$ вкусового обогатителя на основе плодов шиповника - № 7, яблочный сидр с добавлением 50 \% вкусового обогатителя на основе плодов шиповника - № 8, яблочный сидр с добавлением 75 \% вкусового обогатителя на основе плодов шиповника № 9, натуральный яблочный сидр без добавок - № 0.

\section{РЕЗУЛЬТАТЫ ИССЛЕДОВАНИЯ}

Итоговые баллы каждого представленного на дегустацию образца сидра приведены в табл. 2 и на рис. 2.

Таблица 2 - Результаты органолептической оценки

\begin{tabular}{|l|c|c|c|c|c|c|c|c|c|c|}
\hline Номер образца & 1 & 2 & 3 & 4 & 5 & 6 & 7 & 8 & 9 & 0 \\
\hline Внешний вид & 5 & 4 & 4 & 4 & 5 & 5 & 3 & 5 & 5 & 5 \\
\hline Аромат & 13 & 10 & 7 & 13 & 9 & 10 & 8 & 12 & 15 & 14 \\
\hline Вкус & 14 & 10 & 9 & 13 & 17 & 18 & 12 & 15 & 15 & 14 \\
\hline Послевкусие & 8 & 5 & 5 & 6 & 9 & 10 & 5 & 9 & 9 & 7 \\
\hline Итого & 40 & 29 & 25 & 36 & 40 & 43 & 28 & 41 & 44 & 40 \\
\hline
\end{tabular}

Также получены результаты разложения на дескрипторы всех представленных образцов сидра.

При анализе чистого яблочного сидра комиссия выделила следующие дескрипторы: острую яблочную кислоту, винный алкогольный привкус, сладко-горькое яблоко, герань и горькие специи, в том числе анис, вяжущий привкус грецкого ореха и изюм. Неприятных и отталкивающих привкусов обнаружено не было.

При анализе натурального яблочного сидра с минимальным добавлением облепиховой вкусо-ароматической добавки эксперты выделили привкус лимонной кислоты, умеренный привкус облепихи, горьких специй, свежей травы, изюма, горьковатого аниса. В целом продукт сочли гармоничным, однако подчеркнули, что кислотность и горечь приближены к верхней грани сбалансированности.

При анализе натурального яблочного сидра со средним содержанием облепиховой вкусо-ароматической добавки эксперты выделили привкус яблочной кислоты, фруктовый привкус этилацетата, отчётливый, слегка парфюмерный привкус облепихи, древесины, свежей травы и розы, ореховую горечь. Данный продукт эксперты сочли излишне кислым и терпким, поэтому образец не получил высших оценок.

При анализе натурального яблочного сидра с максимальным добавлением облепиховой вкусо-ароматической добавки, эксперты выделили вкус острой яблочной кислоты, едкую лимонную кислинку, цитрус, излишне сильный, парфюмерный облепиховый вкус и аромат, горечь герани, металлический и сивушный привкус. Данный образец эксперты сочли наименее подходящим для представления потребителям, продукт является чересчур кислым, горьким и обладает непривычным, сильным парфюмерным облепиховым ароматом и неприятным сивушным привкусом. 


\section{Внешний вид}

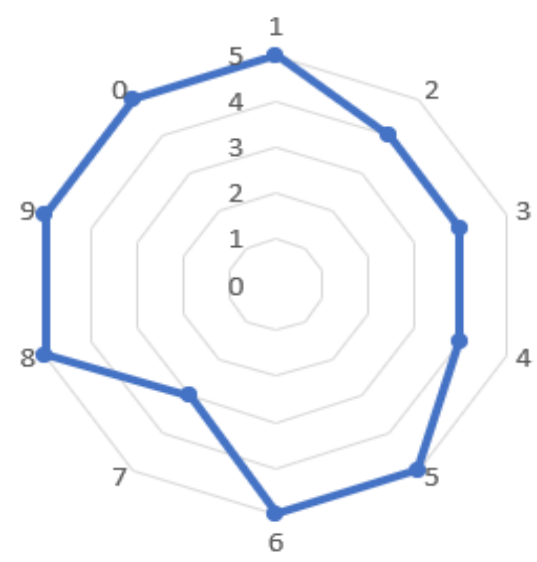

Вкус

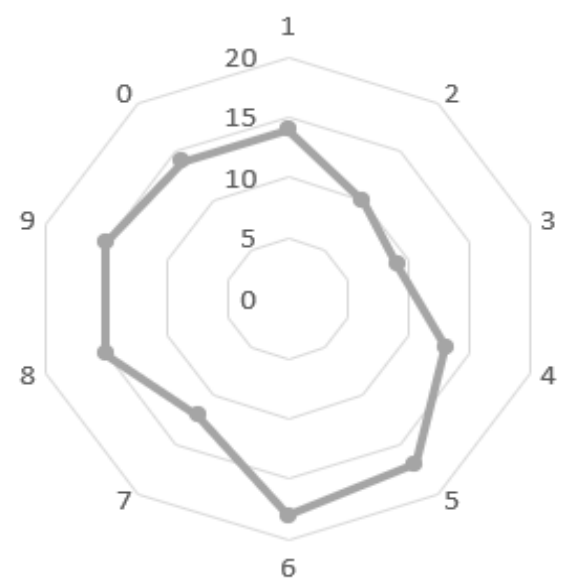

\section{Аромат}

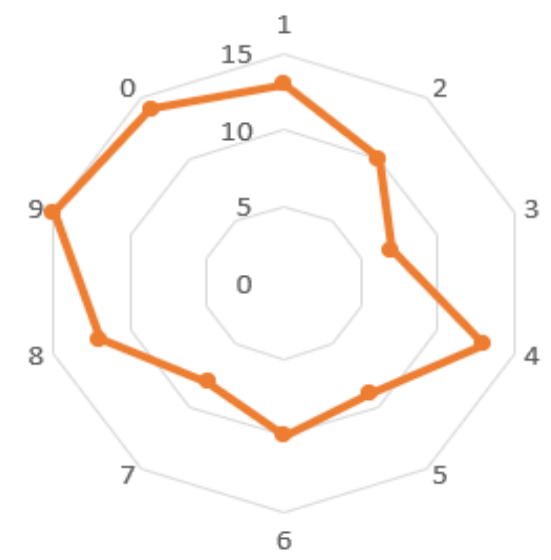

Послевкусие

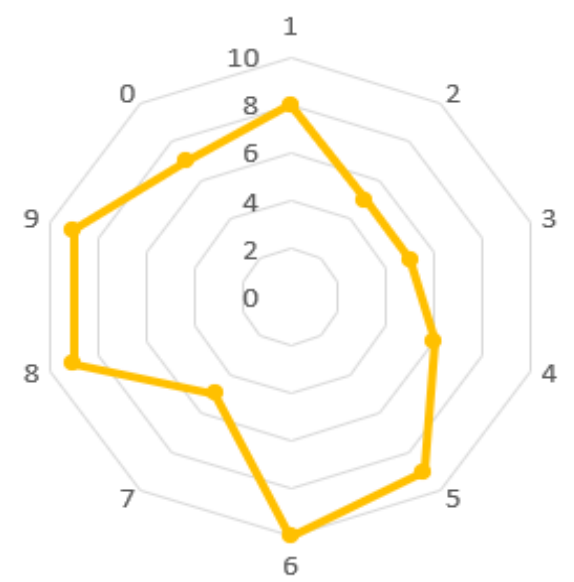

\section{Итого}

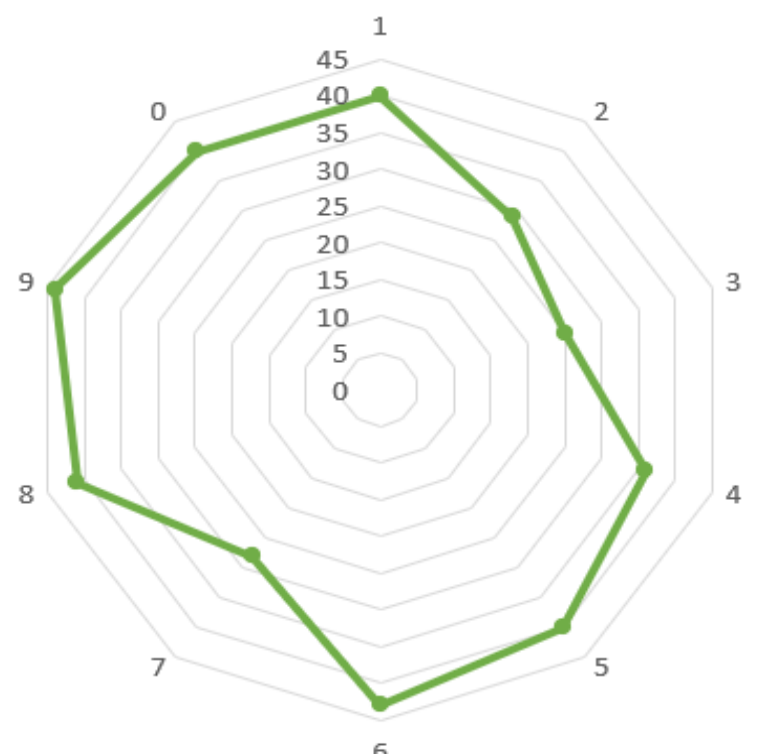

6

Рисунок 2 - Лепестковая диаграмма оценки основных органолептических показателей различных образцов сидра

При анализе натурального яблочного сидра минимальным добавлением вкусоароматической добавки на основе ягод калины, эксперты выделили привкус лимонной кислоты, фруктовый этилацетат, калину, горечь герани, аниса и миндаля, легкий привкус 
дыни. Комиссия посчитала данный образец крайне невыразительным, привкусы ощущаются очень слабо, продукт получился бесхарактерный.

При анализе натурального яблочного сидра со средним содержанием вкусоароматической добавки на основе ягод калины, эксперты выделили привкус яблочной и лимонной кислот, яблочно-анисовый привкус, вкус чёрной смородины, лесных ягод и калины, горечь специй и миндаля, сладкий вкус мёда и изюма, привкус дыни. С увеличением количества вносимого сиропа, комиссия отметила значительное улучшение вкуса, продукт стал насыщенный, сбалансированный по кислотности и горечи.

При анализе натурального яблочного сидра с максимальным добавлением вкусоароматической добавки на основе ягод калины, эксперты выделили привкус яблочной кислоты, фруктовый привкус груши и этилацетата, ноты чёрной смородины, лесных ягод и калины, горечь яблок, специй и герани, сладкий вкус мёда, мелассы и изюма, интересный привкус розы. Максимальную концентрацию натурального сиропа калины в яблочном сидре комиссия выделила как наиболее привлекательную и интересную с точки зрения вкуса, однако с увеличением вносимого сиропа усиливался и специфический аромат ягод калины, что может смущать потенциальных потребителей.

При анализе натурального яблочного сидра с минимальным количеством вкусоароматической добавки на основе плодов балтийского шиповника комиссия выделили привкус древесины, сена, свежей травы, лёгкую горечь. Эксперты описали данное сочетание как наименее интересное из всех представленных. У продукта отсутствует какой-либо яркий вкус, сироп шиповника перебил достоинства чистого яблочного сидра и не смог раскрыться полностью сам. Продукт не рекомендован для реализации.

При анализе натурального яблочного сидра со средним содержанием вкусоароматической добавки на основе плодов балтийского шиповника, комиссия выделила привкус яблочной кислоты, фруктовую свежесть груши, горечь аниса и герани, сладкий вкус печёных яблок, изюма и мёда, шиповника, привкус древесины, сена и розы. Комиссия отметила данный образец как напиток десертный, привкус мёда и печёных яблок оказался самым доминирующим из всего букета, однако насыщенности и телесности по-прежнему недостаточно.

При анализе натурального яблочного сидра с максимальным добавлением вкусоароматической добавки на основе плодов балтийского шиповника комиссия выделили вяжущий привкус грецкого ореха, сладость печёных яблок, мёда, изюма и мелассы, привкус древесины и свежей травы, вкус и аромат чёрной смородины и розы. Данный образец сидра с шиповником эксперты оценили выше всего, продукт приобрёл небольшую терпкость, усилился интересный травянистый привкус, что очень удачно подчеркнуло десертные ноты напитка.

\section{ЗАКЛЮЧЕНИЕ}

Согласно полученным результатам определены образцы натурального яблочного сидра с наивысшей органолептической оценкой. Установлено, что каждый сироп из дикорастущих плодов и ягод, добавленный в различных концентрациях, придаёт яблочному сидру особенный, неповторяющийся привкус. Таким образом, рекомендуемыми соотношениями яблочного сусла и сиропов из натуральных, дикорастущих плодов и ягод являются:

- яблочный сидр с добавлением 25 \% облепихового вкусового обогатителя;

- яблочный сидр с добавлением 50 и $75 \%$ вкусового обогатителя на основе ягод калины;

- яблочный сидр с добавлением 50 и 75 \% вкусового обогатителя на основе плодов балтийского шиповника;

- чистый яблочный сидр. 


\title{
СПИСОК ЛИТЕРАТУРЫ
}

1. Прогресс в направлении стандартизированной системы терминологии аромата вина / Нобле А. С., Арнольд Р. А., Масуда Б. М, Пикор С. Д. [и др.] // Экология и Виноделие. 1984. - № 35 - C. 107-109 [Noble, A. C. Progress towards a standardized system of wine aroma terminology. American Journal of Enology and Viticulture]

2. Колесо аромата вина от Калифорнийского университета в Дэвисе [Электронный pecypc]. - Режим доступа: https://www.thewinecellarinsider.com/wine-topics/wine-educationalquestions/davis-aroma-wheel/ (дата обращения: 30.05.2021)

3. ГОСТ 32051-2013 Продукция винодельческая. Методы органолептического анализа

\section{METHODOLOGY FOR THE GENERALIZED NUMERICAL ORGANOLEPTIC ASSESSMENT OF THE QUALITY OF NATURAL CIDERS ENRICHED WITH SYRUPS FROM WILD FRUITS AND BERRIES}

\author{
A. Koshkina, Master's student, \\ e-mail: anastasija.koskina@gmail.com \\ Kaliningrad State Technical University
A.L. Al'shevskiy, PhD, Associate Professor, e-mail: alshevsky@klgtu.ru
Kaliningrad State Technical University

For the organoleptic evaluation of the quality and taste of cider with different prescription components, two evaluation tables were developed. One of the tables allows you to evaluate the overall impression of the product and give it a qualitative assessment, the second is designed to identify the main flavor notes in cider and establish the typical flavors of the syrups introduced from wild raw materials, similar to the wine and coffee flavor wheel.

Key words: organoleptic evaluation, cider, aroma wheel, descriptors, organoleptic table 